\title{
Helping a Student with Learning Disabilities Memorize Multiplication Facts
}

\author{
Estella P. De Los Santos \\ University of Houston-Victoria, United States of America
}

\begin{abstract}
A sixth grade student's ability to memorize multiplication facts was investigated. The overall goal of the work was to improve the student's understanding and knowledge of basic multiplication facts (0-10) for the zeroes, to fives. There were 66 facts, for example $4 \times 6=24$. The student had been taught multiplication concepts in her elementary years and she did have a basic understand of the meaning of multiplication facts as shown on a pretest. She understood that $4 \times 6$ is a representation of four sets of six or $6+6+6+6=24$. The student's previous knowledge and history were used to develop an individualized education plan to help her have a better understanding of the concept and to memorize basic multiplication facts. The interventions were concrete, semi-concrete, and abstract models of instruction. A pretest was given prior to the sessions and a posttest was given after the sessions. The number of sessions was determined based on the student's ability to learn the concepts. The student was successful at memorizing multiplication facts for the zeroes through fives. The next study will be to help the student achieve automaticity of the multiplication facts.
\end{abstract}

\section{Introduction}

The student was in the sixth grade and this investigation was conducted during the school year and summer after the school year. The student was in a special education classroom at a middle school. She received all of her academic instruction in the special education classroom and went to other classrooms for electives such as art and physical education. The student was diagnosed with mild learning disabilities and autism. She was performing at the third or fourth grade level in reading, writing and mathematics.

According to the student's classroom teacher, the student was having difficulty with several mathematics concepts including fractions. The researcher had previously been working with the 12year old student on renaming and simplifying fractions. The student was able to understand fraction concepts as long as explanations were given and concrete models were used. The student was not able to rename or simplify fractions abstractly as she did not know the basic multiplication facts by memory. She could not rename fractions such as thirds and fourths to twelfths nor simplify fractions such as 4/12 without specific instructions and the use of manipulatives. Therefore, the researcher changed the focus of the lessons from learning fraction concepts to memorizing multiplication facts.

\section{Literature Review}

The National Council of Teachers of Mathematics (NCTM) has set the following as one of the standards for grades 3 through 5: "develop fluency with basic number combinations for multiplication and division" [1]. The NCTM recommends using multiple models such as skip-counting, area models, and relating known facts with those that are not known. According to the NCTM, if the basic facts are not known by the end of the fourth grade, the student "must either develop strategies so that they are fluent with these combinations or memorize the remaining harder combinations" [1]. The Common Core State Standards for Mathematics for Grade 3 states that, "By the end of Grade 3, know from memory all products of two one-digit numbers" [2].

\subsection{Rationale}

It is important that students be able to recall basic multiplication facts because they are necessary in mastering more complex concepts in mathematics [3], [4], [5], [6], [7], [8]. The multiplication facts are especially important in learning fraction concepts such as equivalent fractions, simplifying fractions, and finding common denominators of fractions. Students without learning difficulties usually master the multiplication facts by grades 3 to 4 , while it usually takes children with learning difficulties longer [3], [9], [10], [11].

\subsection{Conceptual Understanding Stages}

A conceptual understanding of basic addition and multiplication facts is essential before students are expected to progress to more complex mathematical topics [12], [13], [14]. Students may progress through 
three stages in learning the meaning of addition and multiplication: concrete, semi-concrete, and abstract stages [15], [16], [17], [18], [19].

In the concrete stage of learning, students use different types of manipulatives to represent sets and counters in sets to understand addition and multiplication concepts. Some sample manipulatives include using bowls for sets and counters such as beans in the bowls, French fry containers for sets and wood sticks or straws as counters, lily pads for sets and frogs on the lily pads for counters, nests for sets and birds in the nests for counters, etc. The different representations for sets and counters in sets may vary as wide as the imagination of the teacher. The multiplication problem " $3 \times 4=12$ " may be explained as 3 sets of 4 or 3 bowls with 4 beans in each bowl. The concept of the product is shown as the sum of " $4+4+4=12 "$. In the semi-concrete stage, drawings are used to represent sets and counters in sets for example circles for sets and dots in the circles as counters. In the abstract stage, students understand addition and multiplication concepts without using manipulatives or drawings [15], [16], [17], [18] [19].

\subsection{Stages in Memorizing Basic Facts}

After students have mastered the conceptual understanding of multiplication, it is important that students memorize basic facts such as " $3 \times 5=15$ during their elementary school years [6]. Having used multiple models for multiplication such as groups, arrays, area models, jumps on a number line, etc, most student will memorize some of the easier basic facts such as $2 \times 3=6$ and the doubles such as $4 \times 4=16$. Memorization techniques should be used to teach the students how to memorize the remaining facts [1]. Memorizing basic math facts will help student in learning other mathematical concepts such as fractions in the middle grades and algebra beyond the middle grades.

Three stages that children usually progress in memorizing basic multiplication facts are described in the research. Phase one involves using counting strategies such as counting blocks, tallies, fingers, etc. Phase two involves using reasoning strategies such as using patterns, logic, relationships in numbers, etc. Phase three is fast and accurate mastery of the multiplication facts [4], [5], [6], [7], [8]. In the third phase, students have memorized the multiplication facts and can recall the product with speed and accuracy. In the first two phases cognition is conscience, deliberate and slow, while in phase 3 cognition is non-conscience, automatic, and fast [4]. Automaticity is the ability to automatically recall the facts without using counting or reasoning strategies [6], [7], [8].

In learning the multiplication facts, students learn relationships between number facts such as multiplying with the numbers zero and one, and multiplying "twin numbers" or "doubles" together such as $2 \times 2,3 \times 3,4 \times 4$, etc. An example using the commutative property of multiplication is learning the relationship between " $6 \times 3=18$ " and " $3 \times 6=18$ " [3], [4], [6], [7]. Learning the commutative property allows students to realize that they only need to memorize half of the facts on a multiplication chart [4], [5].

In phase two, mental reasoning strategies are used to find relationships in the numbers. For example, when multiplying $7 \times 8$ the student may know that $7 \times 7=49$ so therefore $7 \times 8$ would be seven greater or $7 \times 7+7=56$. In reality the student is using the distributive property of multiplication over addition: $7 \times 8=7(7+1)=(7 \times 7)+(7 \times 1)=49+7=56[3],[6]$, [7]. Connections between the arithmetic and algebra should be made by teachers teaching algebra.

\subsection{Two Views on Memorizing Basic Facts}

Rote memorization results in routine expertise where knowledge can be applied to familiar tasks but not with new tasks. Meaningful memorization results in adaptive expertise which can be applied to familiar as well as new tasks. There are two views as to how children learn basic facts. The passive storage view [4] or conventional wisdom view [5] describe how multiplication facts are memorized by rote through repeated practice and reinforcement. The active construction view [4] or number-sense view [5] describe how the facts are memorized meaningfully.

With the passive storage view or the conventional wisdom view, the association between problem and solution does not consider conceptual understanding nor developmental readiness of the child. The learning may be accomplished without counting or reasoning. Positive and negative reinforcements may be used to motivate the students to learn the facts. The fact recall part of the brain does not involve the conceptual and reasoning part of the brain [5]. Phase 1 and 2 can help; but are not necessary for phase 3 . Memorizing the multiplication facts can be achieved through extensive practice such as using flash cards and timed drills alone [4].

With the active construction view or number-sense view, phase 1 and 2 are necessary for phase 3 . Meaningful memorization of the multiplication facts is achieved by creating a rich network of factual, relational, and strategic knowledge. For example, multiplication by "zero" and "one" become rules that lead to automaticity. Multiplication of "doubles" leads to reasoning that helps the students memorize other multiplication facts [4]. Mastery of computational fluency happens by discovering the numerous patterns and relationships that interconnect the basic combinations [5]. Students learn better by learning patterns and relationships rather than by rote memorization. Knowledge that is connected to prior learning is stored in long term memory better than isolated facts [5]. 
With the passive storage view or the conventional wisdom view, phase 3 instruction is achieved by welldesigned and extensive drill. The key to memorization of basic multiplication facts is practice. With the active construction view or number-sense view, instruction in all three phases should include discovery of patterns and relations connecting the basic multiplication facts. The emphasis is on relating new knowledge to previous knowledge. A focus on the structure, rather than memorizing individual facts by rote memory, is more likely to lead to retention of facts [4].

According to the passive storage view or conventional wisdom theory, learning difficulties are due to deficits in the learner [4], [5]. These children are labeled as "learning disabled" and are often characterized as inattentive, forgetful, often confused and unable to apply knowledge. Children labeled as learning disabled rely heavily on counting strategies, may be taught reasoning strategies; but will not invent them on their own, difficulty in learning number facts especially those with numbers higher than 5, and have a high error rate in recalling basic number facts [5].

According to the active construction view or number-sense view, learning difficulties are due to defects in traditional instruction [4], [5]. Although children with learning disabilities do have cognitive impairments, they are capable of learning basic multiplication facts. One reason that learning disabled children have difficulties is because they lack the informal knowledge to develop successful problem solving and reasoning skills. For example, they may lack the informal knowledge to develop an understanding of composition and decomposition which are foundations for learning many mathematical concepts. A second reason is that if the students have been taught with a focus on memorization, they have not developed skills such as looking for patterns and relationships, reasoning skills, nor developed an appreciation for mathematics [5]. Students who have been taught with a focus on memorization may confuse rules such as multiplication by "zero" and "one". They may lose count if they are skip counting and give the wrong answer. Students taught by rote memorization do not think about the reasonableness of an answer and may give an answer that is unreasonable. These strategies make them prone to errors [5].

With the passive storage view or conventional wisdom theory, massive drill and practice is not recommended. It is recommended that students are introduced to one set of basic facts and that the students learn those facts before advancing to another set [5].

With the active construction view or number-sense view, the memorization of basic facts should be integrated with conceptual understanding, problemsolving and reasoning strategies. Students should be encouraged to develop number sense and invent informal strategies. Students should develop meaningful mastery of facts by being encouraged to focus on looking for patterns and relationships among numbers [5].

\section{Methodology}

The single-subject study served to (a) identify the unique needs of the student, (b) guide the selection of instructional content and materials, (c) create an individualized education plan (IEP), (d) monitor student progress, and (e) evaluate learning [20]. Adequate representation of content, appropriate scope and sequence of the content and developmentally appropriate content were addressed to insure accurate measures.

The student's previous knowledge and history were used to develop an individualized education plan to help her memorize multiplication facts (0-10) for the zeroes, ones, twos, threes, fours and fives. There are 11 facts for each multiple with a total of 66 multiplication facts addressed. A pretest showed that the student had a conceptual understanding of basic multiplication facts; but did not have the facts memorized. The researcher used concrete, semiconcrete, and abstract models as interventions to teach the concepts. Skip counting exercises were also used as an intervention. The number of sessions was determined based on the student's ability to memorize the multiplication facts for each multiple (0-10) of zeroes, ones, twos, threes, fours, and fives. A multiple baseline design was used to measure the acquisition of fluency of multiplication facts over time. The student did quite well at memorizing multiplication facts (0-10) for the zeroes, ones, twos, threes, fours, and fives over a three month period.

\subsection{Subject}

The student was in the sixth grade and this investigation was conducted during the school year and summer after the school year. The student is in a special education classroom for all classes except art and physical education at a middle school for grades 6-8. The student was diagnosed with mild learning disabilities and was performing at the third-fourth grade level in math, reading and writing. The student was also diagnosed with mild autism.

\subsection{Materials}

Flash cards with multiplication problems, such as " $4 \times 6$ ", were used to name the problem being addressed. Concrete models that were used included plastic cups for sets and beans for counters. The researcher used lima beans that were painted red on one side of the bean. The red and white beans can be used as natural number or integer counters. The paint 
on one side of the beans helps preserve the beans for years. In the example, " 4 x 6", the problem was read as "four sets of six" and was represented with four cups with six beans in each cup. The addition statement that was illustrated was " $6+6+6+6=24$ ". See Photo 1. The student was asked to write the multiplication and the addition statement on a piece of paper.

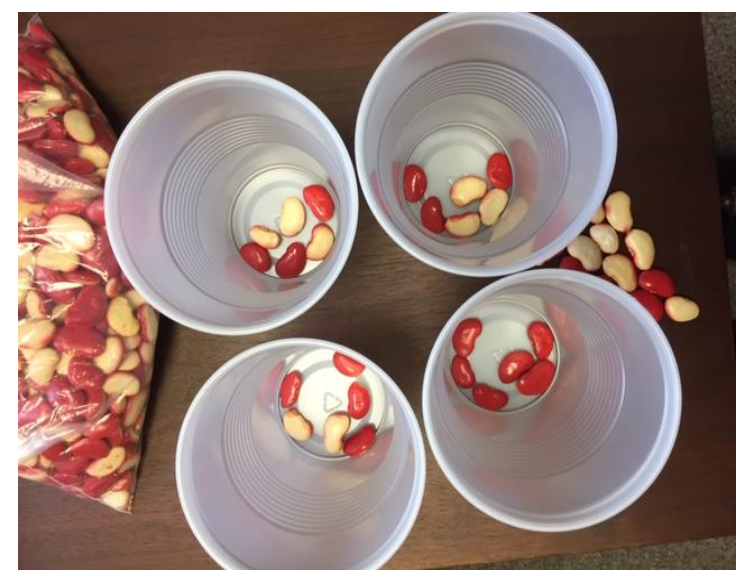

\section{Photo 1. Concrete Models for Multiplication}

Semi-concrete models that were used were flash cards with illustrations. For example, the " $4 \times 5$ " card had the problem printed at the top, an illustration with four circles and five dots in each circle, and the addition statement, " $5+5+5+5$ ", at the bottom of the card. See Figure 1.

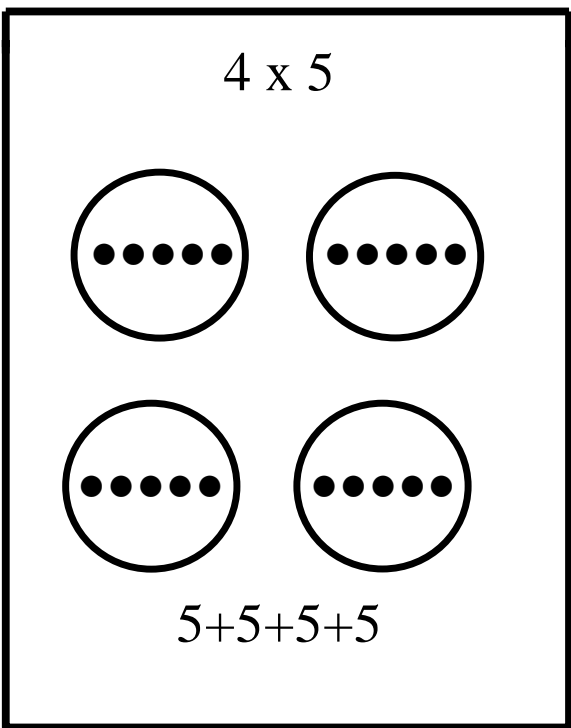

Figure 1. Semi-Concrete Multiplication Flash Cards
Other semi-concrete models that were used were drawings of the student's hands with multiples written on each finger. For example, one multiple of four (1, $4,8,12,16,20,24,28,32,36$, and 40) was written on each finger on the drawing of the student's hands. The hands and fingers were traced with the palms up. As shown in Photo 2, the student pointed to each finger on the drawing as she skip counted by four. See Photo 2.

The student's actual hands and fingers were also semi-concrete models that were used to aid with skip counting. After the student practiced skip counting by four using the drawing, the student would then practice skip counting by four using her hands and fingers. The drawings gave her a mental image of the multiples of four and she was able to transfer those images to her own hands and fingers. When the student finished skip counting by four and was ready to skip count by another factor such as five, she would rub her hands together to "erase" the image in her mind of the multiples of four and next visualize the multiples of five on her fingers. She would then proceed to skip count by a different factor using her fingers.

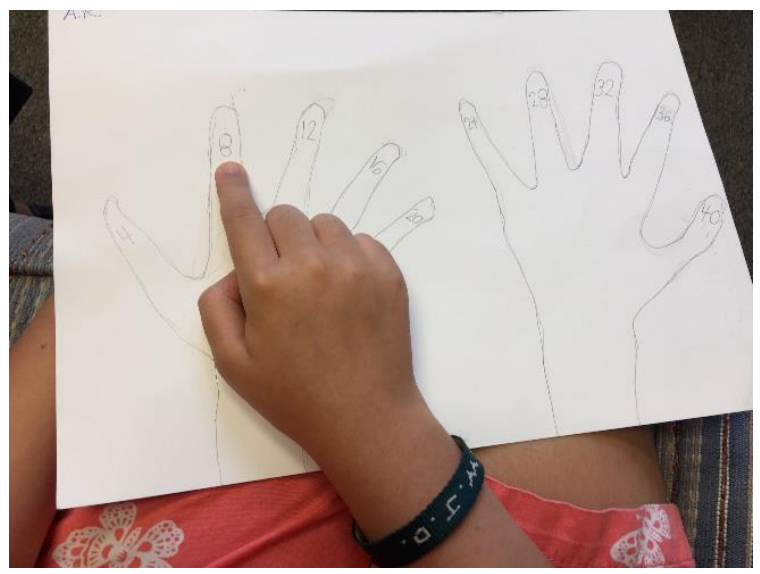

Photo 2. Hand drawings Used to Skip Count

The student used her hands to skip count and to solve basic multiplication facts. She held her hands with the palms up to match the drawings of her hands. The left thumb was the "one", the left small finger was the "five", the right small finger was "six" and the right thumb was "ten". The fingers in between represented the multiples between the thumb and small finger. In Photo 3 , the student was given the problem, "3 3 6". The student was able to show six fingers and remember that the sixth finger, when counting by threes, represented 18 . She was able to transfer the image of the multiples of three from the drawing to her fingers. See Photo 3. 


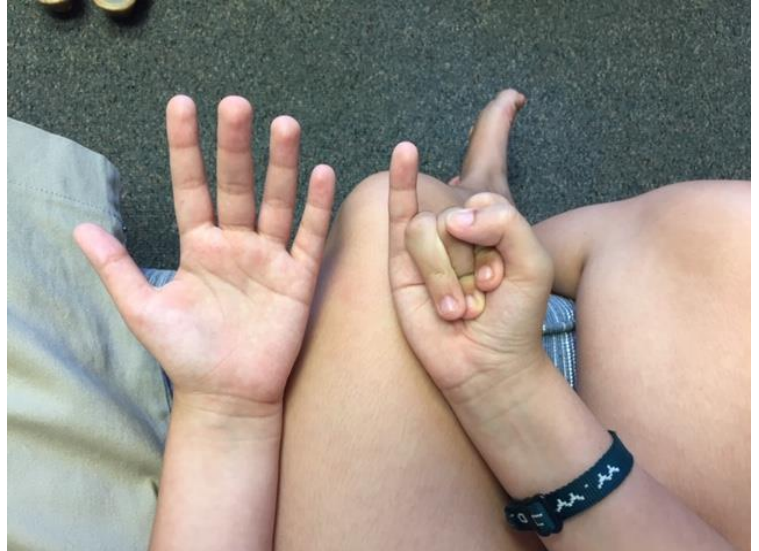

Photo 3. Fingers Used to Recall Basic Multiplication Facts

\section{Results}

The researcher used a pretest and posttest to assess the student's level of understanding of basic multiplication facts $(0-10)$ for the zeroes to nines. The pretest and posttest had three parts. In Part 1 the student was given 20 multiplication facts and asked to state the product. For Part II the student was given five illustrations and asked to write the multiplication fact that corresponded with the illustration. Part III consisted of five problems where the student was given a multiplication fact and asked to provide an illustration for the problem. An individualized education plan (IEP) was developed and administered according to the results of the pretest.

\subsection{Pretest}

Initially the plan was to work on all of the basic multiplication facts, zeroes to nines, with the student. However, Part I of the pretest showed that the student only had $10 \%$ of given basic facts memorized. The student gave the correct product for two problems, out of 20 oral problems. The student seemed frustrated at being asked the multiplication facts and repeated, "I don't know" to all problems. The researcher changed the IEP and only worked on the zeroes to fives with the student because of the time involved in the student learning these facts. It was important to make sure the student was successful in learning one set of facts before proceeding to another set [5] [6].

On the second part of the pretest, the student was asked to write the basic multiplication fact that corresponded to a given illustration. The student was $60 \%$ successful on this part of the assessment. Since the student did not know most of her multiplication facts when the pretest was administered, the student counted all of the dots in the circles to derive the product. This led to miscounting on 2 of 5 problems. In the first problem, the student wrote the correct problem; but counted 8 dots in the picture and wrote, " $3 \times 3=8$ ". After the equation, " $3+3+3=$ ", the student wrote " 8 ". Since the student miscounted the dots, she missed the product as well as the addition equation. See first problem in Figure 2.

Another error made on each problem in Part II of the pretest, was to switch the factors. For example, on the second problem in Figure 2, the student wrote, " $2 \times 4=8$ " instead of " $4 \times 2=8$ ". Although both problems represent the same number of dots, the researcher wanted the student to know the difference between "two sets of four" and "four sets of two". After the equation, " $2+2+2+2=$ ", the student wrote the correct answer, "8". See second problem in Figure 2.

Write the multiplication problem that goes with each picture.

1.

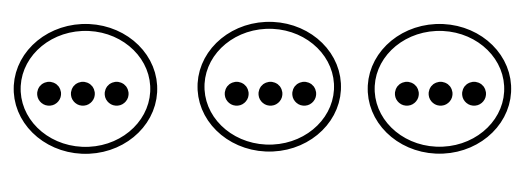

$3+3+3=$

2.

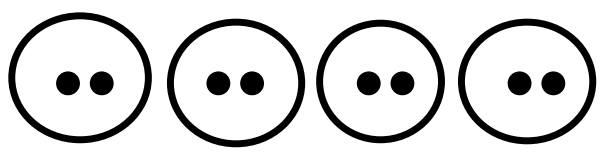

$2+2+2+2=$

Figure 2. Pretest Part II

On Part III of the pretest, the student was given a basic multiplication fact and asked to illustrate the problem using circles and dots. The student was $80 \%$ successful on this part of the pretest. The student drew the correct number of circles and dots in each circle for all of the problems. In problem 6, the student correctly drew 4 circles with 3 dots in each circle for the problem, " $4 \times 3=$ ". See Photo 4 . Not having the basic multiplication facts memorized, the student counted the dots in each picture. This resulted in miscounting the dots in two of the five problems. In problem 7 , the student drew the correct number of sets and dots for " $6 \times 6="$; but miscounted the dots and wrote the solution as " 35 ". See Photo 4. 


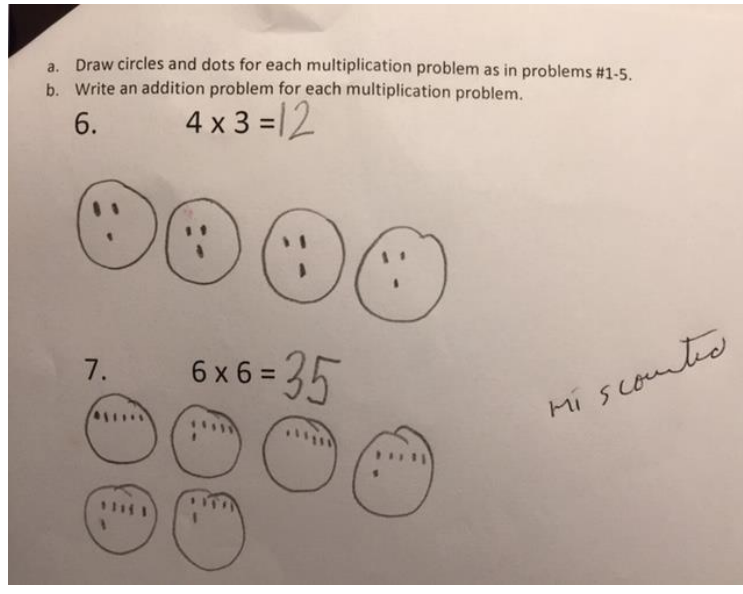

Photo 4. Pretest Part III

\subsection{Individualized education plan (IEP)}

The instruction was divided into three parts: the concrete, semi-concrete, and abstract phases. During the concrete phase, manipulatives were used. The student was given cups to represent the sets and beans to represent the counters. The student had a firm understanding of the concept of basic multiplication facts. She was able to name each problem, such as " $3 \times 4$ ", by its conceptual meaning, "three sets of four". She was able to use the manipulatives to illustrate the problem with three cups with four beans in each cup. See Photo 1. The student had to count each bean to attain the product, since she did not have many of the multiplication facts memorized. From the pretest on multiplication facts, the student was only able to correctly answer a problem with a factor of zero and another with a factor of one. Two 15-minute sessions were needed for instruction and reinforcement of the concept.

The second part of the instructional plan was to teach the student how to skip count. One semiconcrete model that was used was a drawing of the student's hands. See photo 2. Another manipulative that was used were the student's fingers. There was a drawing of the student's hands for the ones, twos, threes, fours, and fives. Each finger represented a product from 1-10 for each factor. The student needed one 15-minute session to draw the hands and understand the order of fingers to count 1-10. Three 15-minute sessions were used by the student to learn how to skip count by two using the drawings with the products on the fingers and skip counting using her fingers without the drawings. Learning to skip count by three and four was more difficult. Seven 15-minute sessions were needed to learn how to skip count by three and seven sessions for the fours. Four 15-minute sessions were used to learn how to skip count by five. In all there were twenty-two 15-min sessions on skip counting. At each session, the previously learned sets were reviewed.

The third part of the instruction plan was recall of basic multiplication facts. The student was first asked to skip count by a specific factor such as skip counting by two. The student relied on her fingers to guide her through the skip counting. She was asked to skip count a second or third time as needed. After the student was successful at skip counting, the student was asked the 10 basic facts, out of order, for that factor. The student was asked all of the basic multiplication facts for the twos, threes, fours and fives during eight 15-minute session. The problems were not timed and the student used her fingers to recall the products. See Photo 3.

\subsection{Posttest}

The results of the posttest showed: 1) The student could state the product of a basic multiplication fact for twos, threes, fours, and fives with 100 percent accuracy. This was a 900 percent increase from the pretest score of 10 percent. 2) The student could write the multiplication fact given an illustration with 100 percent accuracy. This was a 66.6 percent increase from the pretest score of 60 percent. 3) The student was able to provide an illustration for a given multiplication fact with 100 percent accuracy. This was a 25 percent increase from the pretest score of 80 percent. The results on the posttest were for the multiplication facts for zeroes to fives. See Table 1.

\begin{tabular}{|l|l|l|l|}
\hline $\begin{array}{l}\text { Multiplication } \\
\text { facts }\end{array}$ & Pretest & Posttest & $\begin{array}{l}\text { Percent } \\
\text { Increase }\end{array}$ \\
\hline $\begin{array}{l}\text { Give the } \\
\text { solution to a } \\
\text { mult. fact }\end{array}$ & $10 \%$ & $100 \%$ & $900 \%$ \\
\hline $\begin{array}{l}\text { Name the } \\
\text { mult. fact in a } \\
\text { given } \\
\text { illustration }\end{array}$ & $60 \%$ & $100 \%$ & $66.6 \%$ \\
\hline $\begin{array}{l}\text { Provide an } \\
\text { illustration for } \\
\text { a given mult. } \\
\text { fact }\end{array}$ & $80 \%$ & $100 \%$ & $25 \%$ \\
\hline
\end{tabular}

Table 1. Pretest and posttest results

\section{Discussion}

The researcher had previously worked with the student on learning two-digit place value [21], on whole number addition [22] and on three-digit place value [23]. The researcher had begun to work with the student on renaming fractions during the summer after her fifth grade. However, the student was not able to rename fractions or simplify fractions without the use of manipulatives because she did not have the basic multiplication facts memorized. Therefore, the 
researcher began to work with the student on memorizing the basic multiplication facts.

Research shows that students continue to struggle with multiplication facts in the elementary grades. Students who do not develop automaticity with the multiplication facts in the elementary grades, struggle with mathematics in the middle school and are even further behind in high school mathematics. Basic multiplication facts are a building block for understanding higher mathematical concepts; so it is very important that elementary students achieve automaticity [6], [7], [8].

Automaticity is developed by practicing a small set of multiplication facts and mastering that set before proceeding to another set of facts. The recall time should be immediately, within a couple of seconds, rather than taking time to derive the answer [6].

The student was able to learn $100 \%$ of the basic multiplication facts, zeroes to fives. The goal of this study was to learn the basic facts. Automaticity was not a goal because time limits were not imposed and the student was allowed to use her fingers to count. The next study will be to achieve automaticity for the basic multiplication facts. The researcher will continue working with the student, so she may master mathematical concepts at her pace. After the student achieves automaticity with the zeroes to fives, the researcher will work with the student on memorizing multiplication facts for sixes to nines.

\section{References}

[1] National Council of Teachers of Mathematics, Principles and Standards for School Mathematics, NCTM, Reston, Va, 2000, p. 148, 153.

[2] Common Core State Standards Initiative, Preparing America's Students for College \& Career, Mathematics Standards, 2014, Grade 3, p. 23.

[3] Agaliotis, I. and A. Teli, "Teaching arithmetic combinations of multiplication and division to students with learning disabilities or mild intellectual disability: The impact of alternative fact grouping and the role of cognitive and learning factors", Journal of Education and Learning, Vol. 5 No. 4, 2016, pp. 90-103.

[4] Baroody, A.J., N.P. Bajwa, and M. Eiland, "Why can't Johnny remember the basic facts? Developmental Disabilities Research Reviews, Vol. 15 No. 1, 2009, pp. 69-79.

[5] Baroody, A.J. "Mastering the basic number combinations", Teaching Children Mathematics, Aug. 2006, pp. 22-31.

[6] Crawford, D.B., "The third stage of learning math facts: Developing automaticity", R\&D Instructional Solutions, pp. 2003, pp. 1-40. https:// www.rocketmath.com/wp-content/uploads/2016/03/MathFacts-research.1.pdf
[7] Woodward, J, "Developing automaticity in multiplication facts: Integrating strategy instruction with timed practice drills", Learning Disability Quarterly, Vol. 29, No. 4, 2006, pp. 269-289.

[8] Baker, A.T. and J. Cuevas, "The importance of automaticity development in mathematics", Georgia Educational Researcher, Vol. 14 No. 2, 2018, pp. 11-23.

[9] Bouck, E.C., L. Bassette, T. Taber-Doughty, L.M. Flanagan, and K. Szwed, "Pentop computers as tools for teaching multiplication to students with mild intellectual disabilities", Education and Training in Developmental Disabilities, Vol. 44 No. 3, 2009, pp. 367-380.

[10] Geary, D.C., M.K. Hoard, J. Byrd-Craven, L. Nugent, and C. Numtee, "Cognitive mechanisms underlying achievement deficits in children with mathematical learning disability", Child Development, Vol. 78 No. 4, 2007, pp. 1343-1359.

[11] Gersten, R., N.C. Jordan, and J.R. Flojo, "Early identification and interventions for students with mathematical difficulties", Journal of Learning Disabilities, Vol. 38 No. 4, 2005, 293-304.

[12] Van De Walle, J.A., K.S. Karp, and J.M. Bay-Williams, Elementary and Middle School Mathematics: Teaching Developmentally, Allyn \& Bacon, Boston, MA, 2010.

[13] Miller, S.P. and P.J. Hudson, "Helping Students with Disabilities Understand What Mathematics Means", Teaching Exceptional Children, Vol. 39 No. 1, 2006, pp. 28-35.

[14] Hinton, V., S.D. Strozier, and M.M. Flores, "Building Mathematical Fluency for Students with Disabilities or Students At-Risk for Mathematics Failure", International Journal of Education in Mathematics, Science and Technology, Vol. 2 No. 4, Oct. 2014, pp. 257-265.

[15] Mudaly, V. and J. Naidoo, "The concreterepresentational-abstract Sequence of Instruction in Mathematics Classrooms", Perspectives in Education, Vol. 33 No. 1, 2015, pp. 42-56.

[16] Stroizer, S., V. Hinton, M. Flores, and L. Terry, “An Investigation of the Effects of CRA Instruction and Students with Autism Spectrum Disorder", Education and Training in Autism and Developmental Disabilities, Vol. 50 No. 2, 2015, pp. 223-236.

[17] Flores, M.M., V.M. Hinton, S.D. Strozier, and S.L. Terry, "Using the Concrete-representational-abstract Sequence and the Strategic Instruction Model to Teach Computation to Students with Autism Spectrum Disorders and Developmental Disabilities", Education and Training in Autism and Developmental Disabilities, Vol. 49 No. 4, 2014, pp. 547-554.

[18] Miller, S.P., C.D. Mercer, and A.S. Dillon, "CSA: Acquiring and Retaining Math Skills", Intervention in School and Clinic, Vol. 28 No. 2, 1992, pp. 105-110.

[19] Morin, V.A. and S.P. Miller, "Teaching multiplication to middle school students with mild intellectual disabilities, 
Education and Treatment of Children, Vol. 21 No. 1, 1998, pp. 22-36.

[20] Parmar, R.S., R. Frazita, and J.F. Cawley, "Mathematics Assessment for Students with Mild Disabilities: An Exploration of Content Validity", Learning Disability Quarterly, Vol. 19 No. 2, 1996, pp. 127-136.

[21] De Los Santos, E. and B. Patton, "Making Mathematical Place Value Meaningful for a Special Needs Student", International Journal of Technology and Inclusive Education, Vol. 1 No. 2, 2014, pp. 455-458.

[22] De Los Santos, E. and B. Patton, "Using Concrete and Abstract Models to Help a Special Needs Third Grader Master Whole Number Addition", International Journal of Technology and Inclusive Education, Vol. 5 No. 1, 2016, pp. 787-793.

[23] De Los Santos, E., "Helping a Special Needs Student Learn Place Value in the Hundreds", International Journal of Technology and Inclusive Education, Vol. 6 No. 2, 2017, pp. 1108-1116. 